在水交物理方面, 关于冰情变化現象的研究, 已 定了天然水体及被調节河流的各个阶段及其历时的 冰情預报。关于蒸䂭的研究，制定了水面蒸登的計算 方法, 其精确度已能涩足解决水量平衡时的实际需 要。同时在水交学者及气象学者的共同努力下，也郋 展了应用測得的气象要素梯度及热量平衡方法来估計 蒸竟。

此外，在水交化学方面也进行了巨大的工作。現 在覌測水化学的测站共有 800 处, 根据測得的資料, 櫂过分析及棕合, 对于水交化学情况演变的規律, 有 了进一步的認識, 抹且对于經过水庫調节后径流化学 成分的改变, 也能加以計算和預报。

这次会議还明确了, 苏联水文科学的滈展方向是 以地理棕合、工程計算及物理分析三个方向的結合作 为發眼水文科学的必要条件。

苏联有数約 150,000 条河 流，总长 約 $3,000,000$ 公里, 大小湖泊約 200,000 个, 沼澤面积約 2,000,000 平方公里, 由于水道众多, 而国民經济建設的發展, 又不能等待长期来积累資料。苏联学者認为气候要素 及其他地理景覌要素的分布, 具有地带性, 龙其是在 苏联广大的平原地区。因此选择了另一途径, 广泛地 采用水文特征值及其参变数的地理棕合及內插方法, 糩制各种等値䋐圖, 用以幛算未經調查或資料較短的 水道的水文情况, 以供国民䌡济建設的需要。根据地 理棕合的方向，确定了苏联水交站网布置的原則。

工程的方向, 当初是由于水文計算及水利計算实 践中广泛地应用数字統計方法而形成的。統計方法是 研究径流在时間上的变化的, 在进行径流訃算及径流 預报时, 根据統許定律, 就以往出現的水文特征值, 推測将来可能信生的水交特征值。

就已有的資料，对研究年平均径流、径流年內变 化及最小径流的空間分布进行地理的綜合与数学的統 計在苏联已获得广泛的应用。

根据自然环境，应用物理分析方法进行径流形成 过程的試驗研究, 可以說明水量平衡及热量本衡方程 式中各个团素的作用, 抹能指出今后从事理論及实驗 研究的途径.

1952年，在苏联科学院主持下，篔就登展水交科 学的途径, 統計方法与物理分析方法的对比問題, 进 行討論, 未有結果。由于苏联各地径流試 䀫站的 展, 在复杂的自然环境下, 应用物理分析法进行径流 計算与預报, 将日趋重要。而基于地理棕合的經驗的、 牛經驗的近似方法, 将减弱其作用。

在河休演变过程的研究方面, 有綜合形态度量关 系的地貌方向及应用河流动力学分析的物理方向。在 此次大会中明确地指出, 对于河床演变过程的研究,
应邀循形态度量关系与河流动力学相結合、室內試验 与野外覌測相結合二个原則进行。

\section{三 对我国水文科学研究的几点建㦈}

1. 关于水文科学的研究方向, 中国科学院自然区 划顕問 $И$. В. 薩莫伊洛夫敉投認为中国水交科学, 工 程方向的研究已有显著的成精, 地理方向的研究, 扞 不显著, 亟待推进。語重心长, 可供渗考。如按三个 方向相結合的展方針, 中国科学院地学部应即柇取 措施, 加强水文科学地理方向的研究工作。同时科学 院及水利部也应加强水交科学物理方向的研究工作, 相互配合, 水文科学的水平, 才能全面的提高。

2. 为了开展地理方向及物理方向的水交研究工 作, 高等数育部应即在北京大学或南京大学地理系內 筹設陆地水交专業, 侯将来有条件时, 在物理系內設 立水交物理专業。

3. 近代水文科学，分类極細。我国水文科学的弹 展, 除前述研究方向唚不本衡外, 对于开展分支学 科的研究, 亦不平衡。在陆地水文学方面, 仅江河水 交方面的縏潮河段研究較多外, 其他如湖泊、沼摆、 地下水、河口、冰川, 上及水交物理、水交化学等, 也应及早开展研究工作。

4. 为了提高水交科学的水㓅，必須有精密的测䁩 仪器, 我国現在所用的覌测仪器, 比較陈旧, 不适于隐 深科学的研究, 亟应派遺数学及物理基础較好的人日 前往苏联实相研究各种新式水文仪器的制造和应用。

施成熙

(华东水利学院)

\section{克里米亚的强力無織电望远鏡}

苏联科学院列别杰夫物理研究所克里米亚科学研 究站最近制成了一架激新的無䋐电望远鏡。为了建浩 这架無綫电堅远鏡, 使用了一具巨型落地式碗状体的 無电干涉仪。尔用無䋐电波“扫描”法, 当日星掩金 牛座点射电源 $\mathrm{A}$ 时, 用这架無綫电干涉仪对日琵进行 了研究。这架無接电望远鏡是一具水泥浇鄵的、直径 达 31 米的、不轉湤的拁物面碗状体 (反射鏡), 凸面 接地, 以赤繶 $+22^{\circ}$ 的装置指问天穹。尔用分布在扡 物面体 (碗状体) 焦点上的照射子在不大的范围內移 动的方法来控制無綫电接收器的圖式。該無䋐电望远 鏡是在本交作者的領导下, 在 B. A. 烏达利佐夫和 M. $M$ ，嘉普金二位工程师的积極参加下，由科学研究 站和克里米亚科学工作大队协力建成的。

碗状体用水泥浇灌, 其上用金屬數鉱, 以便碗状 体的反射面具有正确的外形, 扭能尽可能地达到高度 精确度。为使反射面的精确度提高，数鋝程度进行了 
好几道。为了数鋳后的外形成为抛物面反射鏡, 制造 了特設的模板。模板为呈扡物面形的金易刀峰状物体。 模板沿和哋物面体的軸相重合的軸自轉, 在灌浇水泥 的过程中使之达到了所要求的外形。水泥表面的精碳 度極高一一数量䄲为 $3-4$ 毫米。碗状体还噴数了一

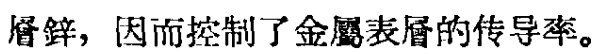

在可浳动的亚形天綫上没置了一具可移动的特制 托架, 以䛧装設、妿置和运轉無电接收器上的照射 子(偑極子和口承物)。框形天䋐沿南北河滑动, 这可 以在子午䤄內操縱無綫电接收器圖式。特制托架連闹 照射子可以沿枉形天䋐作东西向移动。因此, ・可以保 証圖式沿东西向运轉; 㚘且, 当射电源凌过無电接 收器圖式时, 也有可能使之和射电源相随。

两向移动的照射子可以安置在焦点左近的焦面上 任一点。全部运轉, 以及特制托架位置的操縱, 都由 距無电望远鏡不远的小实驗窒的操絽台的自动同步 装置遥程控制。

特制托架（連同照射子一起）可以沿东西向、在 离开焦点土50厘米的范围內移动, 这样, 即相当于移

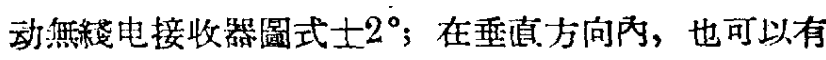
同样㴀围的运动。特制托架按照規定的联接方法能在 預定的范围內（不超过30厘米，即一 $1^{\circ}$ ）自动自南而 北, 或自北而南运轉。当射电源凌过墲綫电接收器圖

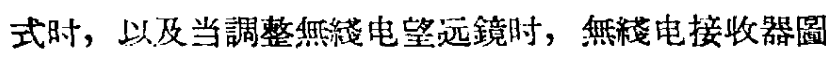
式按照这种方法所能完成的“扫描”对于获取無綫电太 陽和無綫电月亮的全“像”極端重要。特制托架的电子 控制装罝是由 H. B. 米赫也夫工程师設計和安装的。 这架無綫电望远鏡的初次試驗即获得了成功。已絓用 50 厘米波取得太陽無䋐电輻射圖式，等于 $1.2^{\circ}$ (功慗 是 0.5 )。放大系数和計算值極为相近。当輻射天体偏 离焦点时, 圖式破坏, 放大系数降低。

用上述波段，十分可靠地記录了金牛座射电源 $\mathrm{A}$; 强度的等于 $13 \cdot 10^{-24} \mathrm{z} /$ 米 $^{2}$ 赫。

10厘米波的覌測武驗, 以及早先用 3 厘米波所获 得的太陽观測資料都流明了这架望远鏡适于这种極短 波的覌測工作; 此时, 無綫电接收器圖式接近 4.5', 即和預期的計算值相近。

目前开始使用上述的無綫电望远鏡进行極其广泛 的科学研究項目。

金牛座射电源是最有兴趣的研究对象之一，今已 認証它即是超新星 NGC 1952 (敏状星云)。在一篇 科学文献 (1)中, 留提出了十分有力的論据, 認为这一 星云的無定形物体的光波輻射，以及無綫电波輻射均 由相对論性电子在磁場中的运动引起。因此, 以最高

[1] И. С. 史克洛夫斯基, Космичөское радиоизучоние. М.--Л., 1956, ГТТИ.
的精确度，用尽可能寬广的波段，去确定該射电源的 無电輻射区的强度和范围是一件十分重要的工作。 現准备采用双天綫和可变基綫的無䋨电接收器的干涉 法进行測定該射电源的大小范围（以及等䋐电亮度分 布)。将使用这架新無綫电望远鏡作为一个天綫，而另

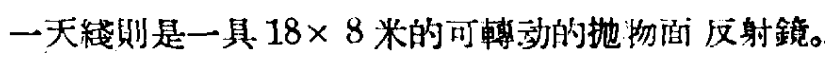

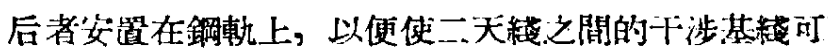
以在相当入的范围內变动。計划完成金牛座射电源的: 21座米波的無䋐电輻射研究，这也是一項有意义的工 作。尔用干涉法可以研究窄波段氢綫的完度分布，抹 可解明蟹状星云周围的氢，主要是非干扰态的客的詳 細分布情况和运动情况。

将来准备試圖探究解状星云的厘米波段偏振現。

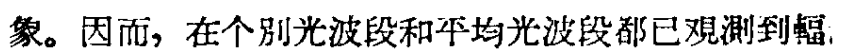
射的偏振。我們有理由預期覌测到厘米波段的类似偏 振現象。但在不久之前，20 厘米波的覌測却得到了 否定的結果。正因为这一系列問題的复杂性以及这一 領域內研究工作的进展, 所以是一項十分有黙义的工 作。

此外，还将研究該無䋨电望远鏡所指向的赤綪 $20^{\circ}$ 泭近一带天区內的其他射电源。

由于新星爆發㙋迹和残核的無綫电輻射的研究也 特別有意义，因此探討新星 NGC 6853 的無螕电輻 射是項很重要的工作。此外，获取反銀心区和有河

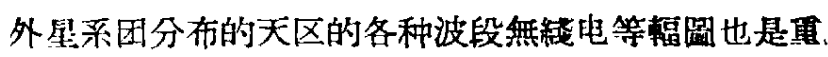
要的。

当太隄进入無綫电接收器圖式之范围內的日子,

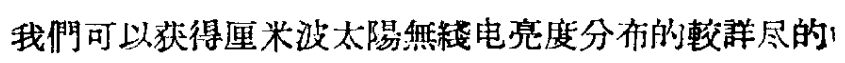
資料，而这些知識在今天还是在假滩阶段。

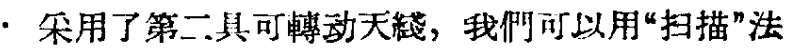
研究分米波日莬。这样，我們可以得到日菟在 $4-5$ 太陽牛径距离內的不均匀性的可靠資料。此外, 利用 这架無綫电望远鏡还可以得到月克然䋹电輻, 可能 还有大行星無綫电輻射的新資料。

目前，这一架無綫电望远鏡已开始按照既定的程序进行工作。

\section{B. B. 維特凯維奇}

\section{〔本 竟 譯自“苏联科学院通报”1957年11月号〕}

\section{苏联的中国学科学中心}

中国人民革命的胜利为六亿人民E大建设性的工 作打下了基础。中国人民在中国共产党的領导下，在 邻造性地运用了䮓克思列宁主义的伟大原理的基啡 上, 根据本国的特点实現了一系列的社会主义改造, 